Cuad. invest. hist. Brocarn. 17 (1991). Págs. 71-84.

\title{
NACIONALISMO Y MASONERÍA EN ESPAÑA (1880-1936)
}

\author{
Pere Sánchez Ferré*
}

\begin{abstract}
RESUMEN.-Esuna aproximaciónal concepto de nacionalismo definido yaen el siglo XIX, refiriéndose a dos tipos de nacionalismo dentro de la masonería española, de una parte el definido por el Gran Oriente Español (G.O.E.) centrado en la defensa de los derechos masónicos de España allende sus fronteras y que en el plano interno rechaza los nacionalismo como el catalán, y una nacionalismo expansionista e incluso colonial, también defendido por el G.O.E., que se convirtió en el abanderado de los valores y la cultura españolas.
\end{abstract}

SUMMARY.-Thispaperconstitutes anapproximationto the conceptofnationalism -which had been defined as such as soon as in the XIXth century-, with special reference to two types of nationalism existing within Spanish Masonry. In the first place, there is the once defined by the Gran Oriente Español (G.O.E.), centered on the defence of the masonic rights of Spain beyond its frontiers and which, with respect to the internal affairs, rejectssuch nationalism as that of Catalonia. In the second place, there is another type of nationalism which will defend expansionand even colonialism, and which, also being sustained by the G.O.E., became the standard bearer of Spanish valuesand culture.

Palabras clave: Masonería, Nacionalismo, Gran Oriente Español, Expansionismo, Cataluña, Cultura.

Key words: Masonry, Nationalism, Gran Oriente Español, Expansion, Catalonia, Culture.

\section{INTRODUCCIÓN}

Para acercarnos al tema del nacionalismo en la masonería española, creemos que en primer lugar es necesario precisar y clarificar qué es lo que entendemos por dicho concepto, del que, desde el pasado siglo hasta la actualidad, se han hecho varias

\footnotetext{
${ }^{*}$ Universidad de Barcelona.
} 


\section{PERE SÁNCHEZ FERRE}

interpretaciones. Evitando entrar en especulaciones teóricas, puesto que no es este el momento para ello, digamos en primer lugar que nos referiremos a dos tipos de nacionalismos dentro de la masonería española, de signo diferente, pero que a nuestro entender designan igualmente dos formas de reivindicar la nación -con o sin Estadoa la que se pertenece y colaborar, en una u otra medida, a su afianzamiento y a la defensa de sus derechos. Así pues, hablaremos de un nacionalismo practicado por el Gran Oriente Español (GOE), básicamente centrado en la defensa de los derechos masónicos y políticos de España allende sus fronteras, y que en el plano interno rechaza los nacionalismos como el catalán, por considerarlos atentatorios a la integridad del Estado y a la hermandad de los pueblos. Ese nacionalismo españolista saldrá en defensa de los intereses españoles allí donde se vean amenazados, como en Cuba, Filipinas y Puerto Rico, identificando la causa de la masonería con la de España.

El segundo aspecto de ese nacionalismo masónico español será su carácter expansionista e incluso colonialista -aunque desde luego no agresivo- del que el GOE será su máximo exponente, conviertiéndose también en abanderado de los valores y la cultura españolas. La obediencia masónica entiende que lo que es bueno para la Orden también lo es para España, aunque discrepa profundamente de la ideología y gestión de sus gobiernos.

En nuestra opinión, el nacionalismo que practican el GOE y las demás obediencias masónicas españolas -a excepción de la Gran Logia Simbólica Regional Catalanaestaba muy próximo al Regeneracionismo y al Krausismo: su objetivo era regenerar España, devolverle su dignidad como pueblo y como nación; llevarla por la vía de un progreso basado en los principios -también masónicos-del humanismo, del liberalismo democrático, el respeto a ultranza del individuo, la hermandad de los pueblos, el pacifismo y el laicismo. Esos eran, en definitiva, los principios sociales y políticos de la llamada masonería latina (la anglosajona seguía su propio camino), de la que el GOE era un ejemplo fidedigno.

El segundo tipo de nacionalismo político dentro de la masonería peninsular fue el surgido en Cataluña con la aparición de la Gran Logia Simbólica Regional Catalana. Dicha obediencia nació reivindicando los derechos nacionales de una nación sin Estado; sus miembros se consideraban oprimidos por el sistema centralista de la Restauración, el cual funcionaba con el mismo rigor en el mundo político que en el masónico, de manera que los gobiernos centralistas de Madrid habían usurpado los derechos históricos de las antiguas regiones y nacionalidades, al igual que las obediencias masónicas, también con sede en Madrid, dirigían de forma centralista y dictatorial toda la vida masónica de las regiones, sin concederles ni un ápice de independencia, ni aún de autonomía. Para esa familia masónica, a un Estado centralista y retrógrado como el español, le correspondía, lógicamente, unas obediencias -los grandes orientes- con las mismas características. Así, los masones de las diferentes regiones sufrían una doble opresión: la de los gobiernos (daba igual conservadores que liberales) y la de los grandes orientes. El paralelismo se establecía incluso en el campo económico, pues argumentaban que el Estado malgastaba los ingresos que obtenía de Cataluña, de igual manera que las obediencias con sede en Madrid explotaban económicamente a sus logias de Cataluña y el resto de España en beneficio exclusivo de los organismos superiores y de sus cúpulas dirigentes. 
Por otras parte, la lucha por la autonomía política y masónica estuvo estrechamente unida a la de la independencia del Simbolismo (la masonería de los tres primeros grados que constituyen las logias).

En cuanto a las ideologías, mientras en la GLSR Catalana predominaban los republicanos federales (por lo menos en la primera etapa), en el GOE había republicanos de varias familias y posteriormente socialistas, pero no federales o regionalistas.

En nuestro país -como en muchos otros-, la masonería constituyó una caja de resonancia de la sociedad, reproduciendo en el mundo masónico lo que ocurría en el mundo «profano» con mayor fidelidad cuanto más politizada estaba la Orden. Y no nos cabe duda de que la penetración de la política y de los políticos en las logias fue el caballo de Troya que ayudó poderosamente a minar desde dentro la propia naturaleza de la masonería, que, no obstante, debía su singularidad y su razón primera de existir al hecho de que era -y debía seguir siendo- una sociedad de tradición iniciática, y no una asociación cultural o política con actividades filantrópicas.

Cada vez que las logias son invadidas por la pasión política, asistimos rápidamente al abandono de las formas tradicionales, basadas en la práctica del Rito, las ceremonias y el estudio de las doctrinas masónicas, todo lo cual cualifica al «hermano» para actuar masónicamente en la sociedad. El paso siguiente, que se da con facilidad, consiste en la aparición de un nuevo tipo de masón, hijo de las circunstancias y no de las «Luces», que no sabe nada de doctrina ni filosofía masónicas, que es incapaz de seguir el ritual propio de su grado, que desconoce sus símbolos y enseñanzas y que, como sucedió durante los años treinta del presente siglo, había puesto todas sus esperanzas en la República, el socialismo o la independencia de Cataluña, pero no en la masonería, a la cual acudía para seguir hablando de política, como lo hacía en la vida «profana». Pero ese no es el tema que nos ocupa; vayamos pues, al objeto de nuestro trabajo.

\section{EL NACIONALISMO DE LAS OBEDIENCIAS MASÓNICAS ESPAÑOLAS ENEL SIGLOXIX}

Aunque toda la prensa y la opinión reaccionaria -básicamente católica-insitió desde mediados del siglo XVIII que la Orden de la escuadra y el compás era «enemiga de España» y conspiraba incansablemente contra sus intereses, lo cierto es que las organizaciones masónicas españolas fueron siempre leales a los intereses políticos y culturales del país, quizá con la matizada excepción de la Regional Catalana -denominada Gran Logia Española a partir de 1921-, que en algunos momentos puntuales jugó en los foros internacionales un papel ambiguo. Durante las guerras por la independencia de Cuba y Filipinas, así como en muchas otras ocasiones, la masonería española dio muestras inequívocas de españolismo, no sólo con sus actuaciones, sino también aconsejando a los gobiernos determinadas estrategias en el campo colonial, tendentes a mantener y acrecentar la presencia española en el extranjero. Queremos decir aquí que no nos hemos propuesto juzgar si ello era bueno o no para el país o la causa de la libertad, sino tan sólo exponer una realidad determinada. 


\section{PERE SÁNCHEZ FERRÉ}

El primer ejemplo de lo que afirmamos lo tenemos en la posición adoptada por las obediencias españolas a raíz del congreso masónico internacional de Lausana, celebrado en 1875, donde las 22 organizaciones masónicas nacionales allí presentes denominados Supremos Consejos- decidieron conceder a una organización cubana protegida por los Estados Unidos -el Supremo Consejo de Colón e Isla de Cuba- la representación oficial de las Antillas españolas, y no a una obediencia española, con el pretexto de que había en España más de una y no sabían cuál era la «regular» ${ }^{1}$. Es decir, que en plena Guerra de los diez Años librándose en Cuba, dichos Supremos Consejos, sin duda bajo la influencia de los Estados Unidos, decidieron dar la independencia masónica a Cuba y Puerto Rico, en detrimento de los derechos masónicos españoles en aquellos territorios. Allí se estableció también que dicha resolución no podía ser alterada «ni aún por la constitución de un Supremo Consejo «regular en España» ${ }^{2}$.

Antes semejante situación, las obediencias españolas no acudieron a aquel primer gran foro internacional de la masonería. Prefirieron el aislamiento internacional a aceptar una decisión masónica, pero también política, que ponía en entredicho los derechos españoles en las Antillas, puesto que nadie ignoraba las implicaciones y las motivaciones políticas que tal resolución conllevaba. Fue así como Cuba y Puerto Rico consiguieron antes las independencia masónica que la política.

$\mathrm{Al}$ año siguiente, el Gran Oriente de España (GODE) -obediencia mayoritaria hasta la irrupción del GOE- denunció los principios adoptados en Lausana y rompió las relaciones con la Gran Logia de Colón, afirmando que el deber de la masonería española era defender «la unión de la masonería y de la patria» ${ }^{3}$.

En 1883 la obediencia cubana protestaba por el hecho de que el GODE les habia acusado de «separatistas» y "de traidores a la patria»"

A causa de la resolución de Lausana, la masonería española vivió aislada y marginada de las organizaciones internacionales más importantes hasta 1904, (aunque mantuvieran relaciones con obediencias extranjeras) cuando el GOE fue admitido en la Federación de Supremos Consejos del Grado 33르, fundada en el congreso de $1875^{5}$.

A pesar de los acuerdos de Lausana, en 1890 el GOE -obediencia hegemónica en España a partir de entonces- afirmaba que auspiciando logias en Cuba, como lo hacían, colaboraban al "mayor progreso de España» y que de ninguna manera se podía renunciar a ello en «aquél nuestro territorio» ${ }^{6}$. Y cuando en febrero de 1895 estalló la insurrección cubana, el Gran Maestre del GOE, Miguel Marayta, declaró que «un asomo de duda de españolismo en cualquiera de sus masones, habría bastado para arrojarle de su seno» ${ }^{7}$.

1 Vid. P. Sánchez i Ferré, La maçconeria a Catalunya, Ed. 62, Barcelona, 1990, pp. 291-292.

2 Grandes Constituciones y Estatutos Generales de la Masonería. Rito E. A.Aceptado, con las Reformas del Convento de Lausana de 1875, Barcelona, 1889, p. 1737.

3 «Ordo», XVIII, n. 22, Bruselas, 1880,pp. 226-231.

4 «ElMallete», III, n. 46,Barcelona, 1 de octubre de 1883,pp. 1-6. Entonces era Gran Maestrodel GODE Antonio Romero Ortíz, que en 1869 fue ministro de Justicia.

5 Boletín Oficial del GOE, n. 152, Madrid, 21 de diciembre de 1904, p. 209.

6 Memoria de los Trabajos realizados. Gran Oriente Español, 1890-1891, pp. 41 y ss.

7 Boletín Oficial del GOE, n. 105, Madrid, 1 de mayo de 1895, pp. 146-147. El comunicado está fechado el 7 de abril. 
A pesar de la crítica situación por la que atravesaba la Orden, a causa de las denuncias de que era objeto por parte de la Iglesia y la reacción, creemos que Morayta no hace aquí una simple declaración de circunstancias, sino que sus palabras son ciertas, como también lo son las que transcribimos a continuación:

«El Gran Oriente Español, así en Cuba como en Puerto Rico y en Filipinas, exige e impone a todos sus afiliados pruebas señaladas de españolismo neto; de donde trabaja en favor de la integridad nacional con todas sus energías ${ }^{8}$.

$\mathrm{Al}$ año siguiente, el mismo Morayta decía que su obediencia estaba «en guerra franca y abierta contra ciertas logias de Cuba con ramificaciones en Puerto Rico que reniegan de la masonería española» ${ }^{9}$.

Poco antes el GOE había enviado una circular a la masonería de los Estados Unidos (donde auspiciaba también algunas logias), en la que sugería a los «hermanos» yanquis que cambiaran de actitud frente al conflicto cubano: «haced que se fijen vuestros compatriotas que si España gobernó Cuba con poca fortuna, eso sólo importa a los cubanos y a los españoles, y no a los extranjeros, como también que los separatistas no son representantes de la libertad de un pueblo, sino vulgares criminales que han destruido la riqueza de extensas comarcas, incendio de poblaciones, violado mujeres y asesinado a gentes indefensas» ${ }^{10}$.

Anotemos que los excesos verbales del GOE estaban tomados precisamente de los que esgrimía demagógicamente la prensa norteamericana cuando se refería a la actuación de las tropas españolas en Cuba. Asimismo, las afirmaciones del GOE eran moneda común en la prensa conservadora y sobre todo integrista, que presentaba a los independentistas antillanos como hordas de salvajes sanguinarios ${ }^{11}$.

Esas y otras muestras de españolismo dio la masonería del país antes, durante y después del conflicto armado. Aunque no estaban de acuerdo con la política colonial de sus gobiernos -la consideraban la peor de todas- las obediencias españolas no eran partidarias ni siquiera de otorgar autonomía política a Cuba y las demás colonias. Defendían su plena integración al Estado Español como miembros de pleno derecho, descartando la concesión de cualquier «status» particular que pudiese propiciar su desvinculación de la Metrópoli. Unicamente de GRLR Catalana, fundada en 1886 y minoritaria en Cataluña, era partidaria de la autonomía para Cuba y, veladamente, de su independencia.

Si en Cuba los masones del GOE y de las otras obediencias -con excepción de la Regional Catalana - eran contrarias a la independencia, en Filipinas las demostraciones de españolismo fueron aún más intensas y también más justificadas; nos explicaremos.

En el Archipiélago oceánico la política masónica española (la del GOE y el GO de España, dirigido por J. M. ․ Pantoja) se centró en la lucha contra el dominio que los frailes ejercian sobre la colonia, pero también tenía por objetivo lograr que se aplicara allí la constitución española de 1876, que se hiciera cumplir la Ley de Prensa y de Asociación

8 Ibidem.

9 Boletín Oficial del GOE, n. 114, Madrid, 20 de septiembre de 1896, pp. 203-205.

10 Ibidem.

11 La Chaine d'Union, IX, n. 3, Paris, febrero de 1874, pp. 137-138. 


\section{PERE SÁNCHEZ FERRÉ}

y que Filipinas consiguiera tener representación parlamentaria, como la disfruta ban Puerto Rico, desde 1871 y Cuba, desde 1876. Es decir, practicaban una política esencialmente asimilista y políticamente reformista, que pretendía convertir Filipinas en una provincia totalmente integrada al conjunto español y pedían a los gobiernos la completa y consecuente españolización de Filipinas. Por esa razón los masones españoles aplaudieron las tímidas reformas iniciadas por el ex Gran Maestre del GODE, Manuel Becerra, cuando siendo ministro de Ultramar, dictó normas para que los filipinos aprendieran la lengua castellana, en febrero de 1889. Y cuando el periódico «Lo Catalanista», de Barcelona, afirmó que no estaban de acuerdo con la medida porque lo que prentendian en Madrid era «extirpar los sentimientos indígenas de los filipinos», la revista filimasónica «La Solidaridad» (órgano de la colonia filipina en España, protegida por M. Morayta y el GOE) contestó que «el regionalismo no tenía razón de ser», porque representaba «el estancamiento, el aislamiento de los idiomas y, por consiguiente, de las ideas» 12 .

Las muestras de nacionalismo español fueron igualmente claras en todo lo referido al Archipiélago, aunque la españolización de la colonia la concebían los masones de la Península -así como la mayoría de los filipinos, por lo menos hasta 1896- en clave laicista, democrática y, en último término, republicana, lo cual constituía el proyecto político del GOE a partir de los años noventa para España y sus colonias. Si en Filipinas no se aplicaba la Constitución y las leyes de la Metrópoli, y no se neutralizaba la hegemonia del clero secular en aquella sociedad colonial, su plena españolización se hacía imposible. De ahí que la masonería, y también la mayoría de republicanos, acusaran a los frailes de ser antiespañoles, puesto que, entre otras cosas, no eran partidarios de que los naturales de Filipinas aprendieran el castellano, de manera que el fraile era el intermediario entre el nativo y la administración española; además, así le mantenían apartado de la «modernidad» europea secularizante...

Sin embargo, los principios asimilistas del GOE y su estrategia anticlerical y reformista para la colonia aceánica atrajo por igual a filipinos reformistas/asimilistas y a independentistas, que de momento jugaban la carta de los primeros, en espera de tiempos más propicios. Todos ellos aprovecharon la plataforma masónica que en la Península les brindó el GOE, para dar la batalla a los frailes y defender los derechos del pueblo filipino. No obstante, parece ser que ya antes de la insurrección cubana la mayoria de sus lideres se convencieron en España de que los gobiernos jamás darían satisfacción a sus demandas, y M.H. del Pilar, M. Ponce, G. López Jaena, etc., pasaron del campo reformista al independentista.

LLegado el momento de la insurrección armada filipina (obra del «Katipunan» y no de la masonería) y de las definiciones claras, una mayoría de masones filipinos adscritos al GOE se inclinaron por la independencia y la insurrección, mientras que el GOE, al

12 «La Solidaridad», I, n. 2, Barcelona, 28 de febrero de 1889, p. 11. «Lo Catalanista» era un diario de Sabadell, escrito en catalán. Sobre la cuestión filipina y la masonería véase también, P. Sánchez Ferté, «La masonería española y el conflicto colonial filipino», en La masonería en la España del siglo XIX, Junta de Castilla y León, Valladolid, 1987, vol.II, pp. 481-496. 


\section{NACIONALISMO Y MASONERIA EN ESPAÑA (1880-1936)}

igual que el GO de España de Pantoja, se mantuvieron allí de donde nunca habían salido: el reformismo y el asimilismo.

Otra cuestión es que el GOE y el propio M. Morayta consintieran muchas cosas a sus amigos y «hermanos» filipinos en aras de la lucha contra los frailes. Ello le costó a la masonería española la práctica inactividad entre 1896 y 1900, acusada de estar comprometida con el «filibusterismo» ${ }^{13}$.

\section{EL NACIONALISMO MASÓNICO CATALÁN Y LA INDEPENDENCIA DEL SIMBOLISMO}

A continuación nos ocuparemos del nacionalismo surgido en medios masónicos catalanes, estrechamente ligado, tanto a las demandas políticas de autonomía y autoderminación de Cataluña en el marco de una república federal, como a las viejas aspiraciones de la masonería simbólica, (de los tres primeros grados) que se sentia dirigida de forma centralista y absolutista desde el llamado Filosofismo, es decir, la cúpula masónica en el Rito Escocés Antiguo y Aceptado, correspondiente a los grados $4^{\mathrm{a}}$ al 33르. Los hermanos de las logias simbólicas, que constituían la estructura básica de las obediencias, venían reclamando desde los años setenta y en particular a partir del congreso de Lausana de 1875 -donde se concedió la independencia al simbolismo- que los grandes orientes dejasen de fiscalizar y dirigir de forma centralista a sus bases simbólicas. Dichas reivindicaciones dieron como fruto la aparición de un movimiento simbolista en el mapa masónico español, con la subsiguiente aparición de diversas obediencias desvinculadas por completo de los grandes orientes: fueron las llamadas grandes logias simbólicas, la mayoría de ellas de base regional y que pronto entraron en agrio conflicto con los tradicionales grandes orientes, que veían en peligro sus seculares privilegios, consecuencia del dominio que, efectivamente, ejercían sobre las logias. La palabra mágica de los grandes orientes para oponerse a los focos regionales era «unión», puesto que gracias a su sistema, -decían- habían hecho posible una muy considerable implantación de la masonería en el tejido político asociativo y cultural de la sociedad española., fundando y amparando logias en los rincones más apartados del país.

El movimiento simbolista posibilitó la creación de organizaciones como la Gran Logia Simbólica Española, de ámbito estatal, fundada en 1878; la Gran Logia Simbólica Independiente Española, en 1881, con sede primero en Sevilla y posteriormente en Cádiz; la ya mencionada GLSR Catalana, en 1886, en cuyos principios se inspiraron en parte organismos de creación posterior, como la Gran Logia de Castilla la Nueva, fundada en 1887; la Gran Logia Regional Galaica, con sede en Santiago de Compostela, en 1888; la Gran Logia Regional de Andalucía, también en 1888, con sede en Córdoba, que

13 En el V Congreso católico, celebrado en Burgos en 1899, todos los obispos españoles firmaron un manifiesto dirigido al presidente del gobierno, en el que se pedía que la masonería fuese declarada ilegal,que se la expulsara de «esta desventurada Nación» y que se reformara la Ley de Asociaciones de junio de 1887: Crónica del V Congreso Católico Nacional Español, Burgos, 1899, pp. 652-662. Es significativo que no fue ésta una acción reducida de sectores ultramontanos y similares, sino que en ella participó toda la jerarquía católica sin excepción. Parece que únicamente la masoneria era capaz de unir a la Iglesia, decantándola hacia la reacción más extrema. 


\section{PERE SÁNCHEZ FERRÉ}

propuso la creación de una Gran Logia Central que coordinase las diferentes regionales; la creación de una Gran Logia Provincial de Málaga, en 1890, y algún otro intento de menor relevancia, como la Gran Logia Simbólica Independiente Ibérica, fundada en 1882 en Málaga o la Gran Logia de España, en Madrid, en $1887^{14}$.

Todos esas organizaciones -a excepción de la Regional Catalana- desaparecieron a finales de siglo y sus reivindicaciones de un Simbolismo independiente no conllevó en ningún caso otras de tipo político, de signo regionalista o nacionalista. Lo que sí estuvo presente en muchos casos fue un republicanismo federal o federalizante, pero que no implicó en ningún caso demandas claras de tipo particularista o nacional. En este caso también, la masonería española actuaba como caja de resonancia de la sociedad, puesto que el único nacionalismo con verdadera entidad y base social hasta entrado el siglo XX fue el catalán.

Ya en 1880, los masones catalanistas de ideología republicana federal fundaron en Barcelona la logia «Avant», que en su declaración de principios decía ser «la primera catalana por su nombre, por sus tendencias y por sus objetivos». Su primer Venerable Maestro fue Rosendo Arús y le siguieron otros como Lorenzo Frau Abrines y Juan B. Salas Anton. De sus filas salió el núcleo fundador de la GLSR Catalana, que impulsó la nueva obediencia bajo los principios de la independencia del simbolismo y la plena autonomía política, borrando de sus estatutos la obligatoriedad de venerar al Gran Arquitecto del Universo, es decir, a Dios.

En su Constitución, la GLSR Catalana incluirá una declaración en la que se dice que la obediencia tiene también por objetivo conseguir que «Cataluña forme un Estado Soberano y Autónomo», sin otras limitaciones que las derivadas del «contrato que establezca y la uno al resto de regiones ibéricas» 15 .

Las sesiones constituyentes de la nueva organización -en las que sólo se habló en catalán- se desarrollaron bajo el lema de «Solidaridad, Autonomía, Prosperidad». La lengua catalana fue declarada la oficial para uso interno de las logias y el castellano para las relaciones exteriores, aunque los Estatutos y Reglamentos Generales se editaron siempre en castellano.

Rosendo Arús fue elegido primer Gran Maestro y Lorenzo Frau, Gran Secretario; también formaron parte de su cúpula destacados dirigentes del federalismo catalanista (divergente del municipalismo pimargalliano) como Cristóbal Litrán, Eduardo Fontseré, Federico Castells, Luciano Navarro y José M. ㅁ Vallès y Ribot, primer presidente del Centro Federalista de Barcelona y corredactor del «Projecte de Constitució per a l'Estat Català», (1883) en el que se inspiró la parte politica de la constitución de la GLSR Catalana. El artículo $5^{\mathrm{a}}$ de la Constitución masónica decía que la obediencia debía trabajar para que en

14 Vid, P. Alvarez Lázaro, «Pluralismo masónico en España», en La masonería en la España del siglo XIX, vol. I, pp. 19-55.

15 Boletín Oficial de la Gran Logia Simbólica Regional Catalana, II, n. 1-7, enero-julio de 1887, pp. $42-64$. 
las demás regiones españolas se constituyeran «grandes logias que proclamen, sostengan y defiendan para su región respectiva, aquello que para Cataluña proclama esta Gran Logia» ${ }^{16}$.

Inmediatamente después de su fundación, todas las obediencias españolas denunciaron la nueva entidad catalana, acusándola de ser una organización política y no masónica, negándose a mantener relaciones con ella. Es significativo que lo que más disgustó a las organizaciones españolas no fue que la Regional Catalana borrara de sus Estatutos al Gran Arquitecto del Universo -hecho grave- sino sus declaraciones políticas nacionalistas. Tampoco gustó a los grandes orientes que hubiera proclamado la total independencia del Simbolismo, pero ese extremo tampoco mereció las iras particulares de casi nadie.

Unos años después, esa actitud no había variado y Morayta, Gran Maestro del GOE, declaraba en el boletín oficial de la obediencia que las doctrinas regionalistas eran «disolventes», porque tendian a «constituir nuevos límites y a formar nuevos estados», calificando las aspiraciones autonómicas de los catalanes como de «retroceso en el camino del progreso ${ }^{17}$. Esa será la posición del GOE hasta bien entrado el siglo XX y que era la propia no sólo de la derecha y del liberalismo, sino también de la mayoría de republicanos, excepción hecha de los federales, y aún con matices.

La Regional Catalana -que a partir de 1900 se llamará Catalana Balear- no fue reconocida por ninguna obediencia nacional ni extranjera, pero a pesar de su aislamiento y de la muerte de R. Arús en 1891, consiguió sobrevivir en el ámbito masónico catalán con relativo éxito hasta finales de siglo, auspiciando seis logias en Barcelona y otras siete en diferentes poblaciones catalanas, algunas de las cuales superaron la crisis finisecular y reorganizaron la obediencia en 1900.

\section{LOS NACIONALISMOS MASÓ NICOS EN EL SIGLO XX}

Al igual que en el siglo anterior, nos encontramos con un tipo de españolismo nacionalista del que, como antes, es abanderado el GOE, de características expansionistas e interesado en las tareas coloniales del país. El otro nacionalismo será, como en el siglo XIX, el basado en las nacionalidades históricas, que también se desarrollará solamente en Cataluña y aún limitadamente, como veremos, puesto que la Gran Logia Regional Cantábrica, fundada en 1902 en Bilbao, fue una creación efímera y exenta de todo signo nacionalista o autonomista.

A lo largo del siglo $\mathrm{XX}$, el GOE seguirá ignorando todo lo referente a las reivindicaciones nacionalistas catalanas e incluso se mostrará insensible a las del Simbolismo, a pesar de ciertos intentos de reformas, demasiado tímidos e ineficaces.

16 Ibidem. Para el proyecto de Constitución del «Estat Català»-que hablaba de una república española y no ibérica-véase, Reunió y Travalls del Congrés Regional Republicà-Democràtic Federalde Catalunya, Barcelona, 1883, pp. 52 y ss.

17 Boletín Oficial del GOE, n. 120, Madrid, 8 de abril de 1902, pp. 40-42. 


\section{PERE SÁNCHEZ FERRÉ}

Como ya se ha dicho, 1904 la obediencia dirigida por Morayta fue admitida por fin en la Federación de Supremos Consejos del Grado 33a, pero su Supremo Consejo no concedió la independencia al Simbolismo y las logias siguieron supeditadas a las directrices de Madrid.

Ciertamente que en los documentos políticos del GOE se hablaba de un proyecto federalizante para España, pero el mismo quedaba completamente diluido por un universalismo también federalizante que hermanaba pueblos y borraba fronteras: se proponía, por una parte, la unión cultural y política de España con la América hispana, (algo así como una «Commonwealth» británica) y por otra propugnaba la unión de los paises latinos europeos, como paso previo a la unión completa del Continente, a la manera de unos Estados Unidos de Europa, todo lo cual tenía sus antecedentes en la masonería española y europea del siglo anterior ${ }^{18}$.

En 1914 el GOE proponía la celebración de un congreso hispanoamericano y en su boletín oficial se decía que España no debía mirar hacia Marruecos, sino a la América hispana:

«Allí se dirigen actualmente las miradas de los que intentan realizar el verdadero ideal español; la conquista del alma americana por medio del respeto y del afecto, estableciendo una comunidad de intereses y aspiraciones entre pueblos hermanos ligados por el origen, por el idioma, por la tradición y por la Historia» ${ }^{19}$.

Por otra parte, la política masónica expansionista del GOE le llevó a auspiciar, en las dos primeras décadas del siglo, un número importante de logias en el extranjero, muy superior a las que tenía en España. Mantenía logias en Estados Unidos, Argentina, Puerto Rico, Filipinas, República Dominicana, Marruecos y Turquía. Entre 1900 y 1910 auspició 14 entidades en España y 59 en el extranjero ${ }^{20}$.

El GOE no sólo daba consejos a los gobiernos en materia colonial (ignoramos si eran tenidos en cuenta) y en temas internacionales, sino que proponía también acciones concretas, como, por ejemplo, la creación de escuelas de lengua española en Turquía, Grecia, Palestina y Siria, paises en los que las comunidades sefardíes eran particularmente numerosas. En la propuesta que dirigieron al Ministerio de Instrucción Pública y al de Estado, se decía que los nexos del idioma habrían de fortalecer los lazos espirituales que nos unían con «nuestros antiguos hermanos» (los judíos) «injustamente arrojados del solar patrio» ${ }^{21}$.

18 A lo largodel último terciodel siglo XIX ya proliferaban las voces partidarias de la unión europea, muy unidas al pacifismo y al movimiento librepensador, estrechamente vinculado a la masonería, tanto en España como en los demás paises del área latina. En el primer míting pacifista celebrado en España (Barcelona, 14 de abril de 1889) se creó la Liga Internacional de la Pazy la Fraternidad de los Pueblos. Una de sus resoluciones abogaba por la unión de todos los pueblos europeos en una federación, en la que se garantizase «el armónico desartollo de todos los intereses individuales y colectivos». VéaseP. SánchezFerré, La maçoneria a Catalunya, pp. 140-146.

19 Boletín Oficial del GOE, n. 267, Madrid, 29 de julio de 1914, p. 111.

20 Véase J.A. Ferrer Benimeli, "Las Logias del Grande Oriente Español», en Masonería, Política y Sociedad, CEHME, Zaragoza, 1989, vol. II,pp. 1033-1082.

21 Boletín Oficial del GOE, n. 337, Madrid, 31 de mayo de 1920, pp. 86-87. 


\section{NACIONALISMO Y MASONERÍA EN ESPAÑA (1880-1936)}

Otro aspecto del nacionalismo que practicó el GOE fue defender la presencia masónica y cultural de España en Filipinas y Puerto Rico, ocupadas por los norteamericanos desde 1898. En las logias de las antiguas colonias se trabajaba en español y no en inglés, y sus miembros eran poco amigos de la ocupación yanqui. Esa política masónica le acarreó al GOE muchos e importantes problemas en los foros internaciones de la Orden.

Cuando en 1924 la Asociación Masónica Internacional conminó al GOE a que abandonara sus logias de Puerto Rico y Filipinas, la obediencia española respondió que lo haría cuando esos paises fueran independientes, y no antes ${ }^{22}$.

En la logia «Hispanoamericana», de Madrid, se decía en 1928 que España debía «volver a América», incrementando los intercambios de todo tipo, pues una «España capitalista» habria de cumplir un papel mucho más provechoso para españoles y americanos que el que estaba realizando los Estados Unidos.

Esas eran -decían- «las grandes batallas culturales y financieras del momento (...) España era entonces el tercer lado de ese triángulo cuyos otros dos son la América Central y antillana y la América del Sur» ${ }^{23}$.

Es seguro que el GOE comulgaba sin reparos con la propuesta de su logia madrileña, en la que estaban afiliados masones de Hispanoamérica.

En cuanto a la vida interna de la masonería española, no es sino a partir de 1920 que, procedentes de Cataluña, comienzan a oirse en el seno del GOE las primeras voces que piden la independencia del simbolismo y la creación de una Gran Logia autónoma en aquél territorio. Al año siguiente, la antigua Catalana Balear se convierte en una obediencia de ámbito estatal bajo el nombre de Gran Logia Española (GLE), con sede igualmente en Barcelona, que sigue propugnando la independencia del Simbolismo y estructuras federales, tanto para la masonería como para el Estado Español. Así, pasan a convertirse en la alternativa para todos aquellos masones o logias que aspiran a emanciparse del GOE y de su Supremo Consejo, que sigue invariable en su tradición centralista. La situación se hace más preocupante para el GOE porque ese mismo año ha sido fundada la Asociación Masónica Internacional, en Suiza, en la que la GLE ha conseguido la representación oficial de España, en detrimendo del GOE.

Aunque las voces disconformes son aún pocas, ante el doble peligro de la rivalidad interior de la GLE y el riesgo de quedar marginados de la AMI, los dirigentes de la obediencia española deciden -diríamos que precipitadamente- reorganizarla por completo y en 1922 la convierten en siete grandes logias regionales, que en teoría son independientes del Filosofismo y del Supremo Consejo del Grado 33ª. Dichas entidades habian de controlar las logias de sus respectivas regiones y legislar en todo lo referente al Simbolismo.

Que la reforma emprendida no respondía a otro objetivo que adaptarse a los principios que regían en la AMI en materia de Simbolismo, lo demuestra el hecho de que en la división masónica que hicieron del territorio español, Cataluña (Gran Logia

22 Véase P. Sánchez Ferré, «Masonería y colonialismo español», en La masonería y su impacto internacional, Universidad Complutense de Madrid, 1989, pp. 21-22.

23 Boletín oficial del GOE, n. 23, Sevilla, 10 de agosto de 1928, pp. 7-15. 


\section{PERE SÁNCHEZ FERRÉ}

Regional del Nordeste) era unida a Baleares y Aragón, excepto Teruel, que pasaba a la Regional de Levante... Asturias, Galicia y Euzkadi formaban la GLR del Noroeste. En un futuro se esperaba hacer algunas reformas a ese dislocado mapa regional, como asignar a la proyectada Regional del Norte los territorios de Santander, Euzkadi, Navarra y La Rioja, lo cual carecía igualmente de toda justificación política o históri$\mathrm{ca}^{24}$.

Por su parte, la GLE se dio una Constitución en la que se abogaba por el federalismo y la creación de grandes logias regionales, pero lo cierto es que, a pesar de hacer breves y escasas declaraciones de "regionalismo» en su boletín oficial ${ }^{25}$, la mayoría de sus bases y dirigentes estuvieron mucho más ocupados en la lucha por el advenimiento de la República y de su afianzamiento, que en el «problema catalán». Las únicas grandes logias que organizaron fueron las de Canarias y Cataluña.

En cuanto al GOE, su actitud frente al nacionalismo de las regiones históricas siguió siendo el mismo hasta la Segunda República, aunque en 1934 su GLR del Nordeste, con sede en Barcelona, decretó la cooficialidad del catalán, junto con el castellano, para los asuntos internos de sus logias.

De hecho, el único bastión nacionalista antes de 1931 fue la logia «Justicia», de Barcelona, fundada bajo los auspicios de la Catalana Balear, en 1918. En ella se habían afiliado catalanistas y algunos independentistas, como Ramón Arrufat Arrufat. Poco después de su creación, fueron denunciados al GOE por su logia de Barcelona, «Lealtad», acusándoles de que trabajaban para «conseguir la independencia de Cataluña» ${ }^{26}$.

Andrés Nin -fundador del POUM- fue Venerable Maestro de la «Justicia» y uno de sus fundadores; Rafael Vidiella, fundador del PSUC, fue iniciado en la logia en 1921.

Los «excesos» nacionalistas de esta entidad fueron motivo de varios conflictos con su obediencia; en 1924 la GLE amonestaba a sus miembros recordándoles que debían dirigirse a los órganos superiores de la obediencia siempre en castellano ${ }^{27}$.

El segundo núcleo nacionalista catalán lo constituyó la logia «Themis», instalada oficialmente en Barcelona, en diciembre de 1930, también auspiciada por la GLE e impulsada por miembros de la «Justicia». Muchos de sus componentes lo eran también del partido separatista «Estat Català», como Jaime Miravitlles, J. Mías Codina, Roc Boronat, Amadeo Oller, Marcelino Perelló o el citado Arrufat Arrufat.

El Gran Maestro de la GLE, Francisco Esteva, aseguró a la «Themis» que cuando se proclamara la Generalitat, la logia jugaría un importante papel gracias a su compo-

24 Véase J. A. Ferrer Benimeli, Masoneria española contemporánea, SigloXIX, Madrid, 1980, vol. II, pp. 54-58.

25 Aún en 1924, la GLE acusaba al clero de la existencia del separatismo en Cataluña, en un tono francamente anticatalanista: Boletín Oficial de la GLE,n. 9, Barcelona, 20 de mayo de 1924,p. 10. En 1932 sedefinía simplemente «regionalista», cuando el término común entonces era «catalanista»o «nacionalista»: Boletín Oficial de la GLE, abril de 1932, p. 7 y 16.

26 Archivo Histórico Nacional. Salamanca, Sec. Masoneria (AHNS), Leg. 619 A, exp. 10.

27 Boletín Oficial de la GLE, n. 24-25-26, Barcelona, junio-julio-agosto de 1925, p. 14. 
nente nacionalista. No obstante, cuando sus miembros hablaban en catalán en las asambleas de la GLE, surgía las protestas de gran número de los asistentes, pues la mayoría entre de sus dirigentes eran refractarios al nacionalismo catalán.

Con todo, la «Themis» emprendió en solitario la tarea de catalanizar la vida masónica de Cataluña; fue la primera en editar impresos y hojas de iniciación en catalán y los trabajos de logia y las actas de los mismos fueron siempre realizados en esa lengua ${ }^{28}$. Pero cuando, en febrero de 1932, la GLE se negó a aprobar la cooficialidad del catalán, la «Themis» abandonó la obediencia y siguió en activo como independiente. En ese período se habló en sus sesiones de organizar un llamado "Comitè Nacional de Catalans Revolucionaris», de claro signo separatista y relacionado con estrategias de «Estat Català». También se proyectó crear una "Gran Lògia Nacional Catalana», con el objetivo de constituir una obediencia catalana independiente de las dos organizaciones españolas (GOE y GLE) ${ }^{29}$.

No obstante, el proyecto no cuajó y cuando en septiembre de 1933 la GLE creó la Gran Logia de Catalunya -organismo autónomo para aquella nacionalidad- y decretó por fin la cooficialidad del catalán, la «Themis» se reincorporó a la obediencia, como miembro de la citada Gran Logia; contaba entonces con 17 miembros. Poco después la GLE se trasladaría a Madrid, con lo que culminaría la «españolización» de la obediencia nacida en 1886.

La reintegración de la logia a la obediencia y el ambiente más sensible a las reivindicaciones nacionales dentro de la GL de Cataluña no suavizó las aspiraciones de la «Themis». Poco después de la victoria del Frente Popular, sus miembros intentaron de nuevo crear una obediencia catalana independiente. El mes de marzo de 1936, A. Oller, M. Perelló y seis «hermanos» más de la logia -la mayoría de ellos vinculados a «Estat Català»-, fundaron la logia «Catalunya» n. 1 i el «Gran Orient Independent Català» ${ }^{30}$.

Pero tampoco esta vez el éxito acompananía a los masones separatistas, pues al conocerlo la GL de Catalunya, Oller y Perelló fueron expulsados de la masonería y los demás componentes del grupo fueron suspendidos de afiliación masónica por un año. Simultáneamente, la GLE y el GOE enviaron sendas circulares a sus logias de España, así como a las obediencias extranjeras, advirtiendo que un grupo de "hermanos» expulsados había fundado una «organización irregular», que nada tenía que ver con la masonería. Poco después, el boletín oficial de la AMI daba la noticia, comentando que frecuentemente aparecían en Barcelona grupos masónicos irregulares, fundados por iniciativa de descontentos o expulsados: «Avisamos a nuestros miembros a fin de que no sean sorprendidos en su buena fe» ${ }^{31}$.

28 AHNS, Leg. 609 A. La «Themis» propuso al gobiernocatalán que hiciese una purga del funcionariado, pues decían que todo era anticatalanista. En la «tenida» del 12 de julio de 1932 se dijo que sólo el $8 \%$ del magisterio no era reaccionario y anticatalán.

29 AHNS, Leg. 609 A, actas del 16, 23 y 30 de mayo de 1933.

30 AHNS, Leg. $618 \mathrm{~A}$, exp. 9.

31 «Bulletin. Organ Officel de l’AMI», n. 57, abril-junio de 1936, pp. 216-217. 


\section{PERE SÁNCHEZ FERRÉ}

Este fue el último intento de crear una entidad masónica independiente de las obediencias españolas, surgido de sectores ultranacionalistas, que aspiraban a la independencia política y masónica de Cataluña.

Aunque en 1937, A. Oller y M. Perelló fueron amnistiados y pudieron retornar a la Orden, la guerra impidió cualquier otro intento separatista en la vida catalana y española, pues los «hermanos» que no estaban luchando en el frente, se dedicaron a tareas humanitarias y a recabar ayuda en el exterior por medio de las obediencias extranjeras, cuya solidaridad se hizo efectiva y proporcionó una ayuda importante a la causa republicana. 